\title{
Histone Deacetylase Activity and Phytotoxic Effects Following Exposure of Duckweed (Lemna pausicostata L.) to Apicidin and HC-Toxin
}

\author{
Hamed K. Abbas, John W. Gronwald, Kathryn L. Plaisance, Rex N. Paul, and Yin W. Lee
}

\begin{abstract}
First and fourth authors: U.S. Department of Agriculture-Agricultural Research Service, Southern Weed Science Research Unit, Stoneville, MS 38776; second author: U.S. Department of Agriculture-Agricultural Research Service, Plant Science Research Unit, St. Paul, MN 55108; third author: Department of Agronomy and Plant Genetics, University of Minnesota, St. Paul, MN 55108; and fifth author: School of Agricultural Biotechnology and Research Center for New Bio-materials in Agriculture, Seoul National University, Suwon 441-744, Korea.

Current address of H. K. Abbas: U.S. Department of Agriculture-Agricultural Research Service, Crop Genetics \& Production Research Unit, Stoneville, MS 38776.

Accepted for publication 23 August 2001.
\end{abstract}

\section{ABSTRACT}

Abbas, H. K., Gronwald, J. W., Plaisance, K. L., Paul, R. N., and Lee, Y. W. 2001. Histone deacetylase activity and phytotoxic effects following exposure of duckweed (Lemna pausicostata L.) to apicidin and HC-toxin. Phytopathology 91:1141-1148.

The effects of two cyclic tetrapeptide fungal toxins, apicidin (from Fusarium spp.) and HC-toxin (from Cochliobolus carbonum), on duckweed (Lemna pausicostata L.) were examined. Both toxins inhibited histone deacetylase (HD) activity from duckweed plantlets; the effective concentration $\left(\mathrm{EC}_{50}\right)$ for inhibition of $\mathrm{HD}$ was 5.6 and $1.1 \mu \mathrm{M}$ for apicidin and HC-toxin, respectively. Approximately 65 and $85 \%$ of in vitro HD activity was inhibited by $50 \mu \mathrm{M}$ apicidin or HC-toxin, respectively. Exposing duckweed for $72 \mathrm{~h}$ to apicidin or HC-toxin (25 or $50 \mu \mathrm{M})$ enhanced cellular leakage, impaired chlorophyll synthesis, and inhibited growth (cell division). At equivalent concentrations, the effects of HC-toxin were more pronounced than those of apicidin. In fronds, $72 \mathrm{~h}$ of exposure to $50 \mu \mathrm{M}$ apicidin resulted in chloroplast deterioration indicated by loss of orientation and excess starch accumulation. In roots, a 72-h treatment with $50 \mu \mathrm{M}$ apicidin resulted in the loss of the root cap and increased vacuolization and starch accumulation in plastids.
Apicidin (Fig. 1) is a cyclic tetrapeptide toxin recently isolated from Fusarium sambucinum and $F$. semitectum $(22,26)$. F. sambucinum $(11,20)$ causes dry rot of potato and fruit blotch of strawberry, whereas F. semitectum (9) causes pod and collar rot of soybean. Although both fungal species produce apicidin, it has not been established that this toxin plays a role in plant disease. Feeding apicidin to rats causes hemorrhagic symptoms (22). Protozoan parasites of the subphylum Apicomplexa, including Cryptosporidium parvum, Toxoplasma gondii, and Eimeria tenella, are very sensitive to apicidin (7). It has been proposed that the antiprotozoan activity of apicidin is due to its ability to inhibit histone deacetylase (HD) (7). By regulating the level of acetylation of core histones associated with DNA, HD is thought to play a key role in regulating nuclear transcription of genes. The results of Darkin-Rattray et al. (7) suggest that apicidin prevents in vitro development of intracellular apicomplexan parasites by causing hyperacetylation of core histones.

HC-toxin (Fig. 1), a cyclic tetrapeptide peptide isolated from Cochliobolus carbonum (formerly Helminthosporium carbonum) race 1 , causes leaf spot in maize that is homozygous recessive at the $\mathrm{Hm}$ locus (23). In vitro assays indicate that HC-toxin is a potent inhibitor [effective concentration $\left(\mathrm{EC}_{50}\right) \approx 5 \mu \mathrm{M}$ ] of maize $\mathrm{HD}(5)$. It has been proposed that by blocking HD and thereby interfering with the regulation of gene expression, HC-toxin suppresses the ability of susceptible maize genotypes to mount a defense response to the invading fungus $(5,23)$. Other research has shown that $\mathrm{HC}$ toxin inhibits HD from apicomplexan parasites (7), mammalian cells (5), and the fungus Physarum polycephalum $(5,18)$.

Corresponding author: H. K. Abbas; E-mail address: habbas@ars.usda.gov

Publication no. P-2001-1012-01R

This article is in the public domain and not copyrightable. It may be freely reprinted with customary crediting of the source. The American Phytopathological Society, 2001.
The objectives of this research were to investigate the in vitro effects of apicidin and HC-toxin on duckweed HD, examine phytotoxic effects of both toxins on duckweed at the whole plant level, and characterize the effects of apicidin at the ultrastructural level. Duckweed (Lemna pausicostata L.) was chosen as a bioassay species because previous research demonstrated its utility as a model plant for investigating the effects of fungal toxins at both the whole plant and ultrastructural level $(2,3,21,27)$. A preliminary report of the effects of apicidin on duckweed were presented earlier (1).

\section{MATERIALS AND METHODS}

Chemicals. The synthetic peptide fragment, Ac-Gly-Ala-LysArg-His-Arg-Lys-Val- $\mathrm{NH}_{2}$, used as a substrate for measuring HD activity, was synthesized and purified by the Microchemical Facility, Institute of Human Genetics, University of Minnesota. $\left[{ }^{3} \mathrm{H}\right]$-acetic anhydride (specific activity $64 \mathrm{mCi} / \mathrm{mmol}$ ), used for labeling the synthetic peptide, was purchased from ICN Biomedicals (Costa Mesa, CA). Prep Sep $\mathrm{C}_{18}$ columns were purchased from Fisher Scientific (Hanover Park, IL). HC-toxin and Sephadex G-25 were purchased from Sigma Chemical (St. Louis). Apicidin was isolated and purified from Fusarium spp. as described in detail by Park et al. (22). Apicidin was also provided by Merck Research Laboratories, Rahway, NJ.

Labeling of HD substrate. The synthetic peptide fragment (residues 14 to 21) of histone H4 (Ac-Gly-Ala-Lys-Arg-His-ArgLys-Val- $\mathrm{NH}_{2}$ ) was chemically acetylated as described by Sendra et al. (25) with modifications. Purified peptide $(10 \mathrm{mg})$ was dissolved in $0.2 \mathrm{ml}$ of $20 \mathrm{mM}$ triethanolamine ( $\mathrm{pH} \mathrm{8.2)} \mathrm{and} \mathrm{added} \mathrm{to}$ $78 \mu \mathrm{l}$ of $\left[{ }^{3} \mathrm{H}\right]$-acetic anhydride. The reaction was incubated for $30 \mathrm{~min}$ at $23^{\circ} \mathrm{C}$, and $50 \mu \mathrm{l}$ of $1.25 \mathrm{M} \mathrm{HCl}$ and $2.0 \mathrm{ml}$ of ice cold acetone were added to precipitate the peptide. The solution was centrifuged $(2,000 \times g, 10 \mathrm{~min})$ at $4^{\circ} \mathrm{C}$. The supernatant was dis- 
carded, and the pellet was washed twice with $1.0 \mathrm{ml}$ of acetone. The labeled peptide was resuspended in buffer A (15 mM Tris$\mathrm{HCl}, \mathrm{pH} 7.8,10 \mathrm{mM} \mathrm{NaCl}, 0.25 \mathrm{mM}$ EDTA, $10 \mathrm{mM}$ 2-mercaptoethanol, and $10 \%$ glycerol). To remove contaminating $\left[{ }^{3} \mathrm{H}\right]$-acetic acid, 0.3-ml aliquots were applied to Prep Sep $\mathrm{C}_{18}$ columns equilibrated in $\mathrm{H}_{2} \mathrm{O} / 0.1 \%$ trifluoroacetic acid (TFA). Columns were washed with $2.0 \mathrm{ml}$ of $\mathrm{H}_{2} \mathrm{O} / 0.1 \%$ TFA, and the peptide was eluted with $2.0 \mathrm{ml}$ of $70 \%$ acetonitrile $/ 0.1 \%$ TFA. The solvent was removed by evaporation under a stream of nitrogen, and the labeled peptide was dissolved in buffer A. The specific activity of the acetylated histone $\mathrm{H} 4$ peptide was $6.6 \mu \mathrm{Ci} / \mu \mathrm{mol}$.

Bioassays. Duckweed bioassays were conducted as described by Tanaka et al. $(27,28)$. Ten duckweed plantlets were transferred to small petri dishes $(3.5 \mathrm{~cm}$ ID) containing $3 \mathrm{ml}$ of the following: half-strength Hutners medium (12) alone, medium containing $0.05 \%$ dimethyl sulfoxide (DMSO), or medium containing $0.05 \%$ DMSO plus 25 or $50 \mu \mathrm{M}$ apicidin or HC-toxin. Petri dishes were covered with three layers of cheesecloth and incubated at $25^{\circ} \mathrm{C}$ under continuous light $\left(115 \mu \mathrm{E} \mathrm{m}^{-2} \mathrm{~s}^{-1}\right)$ in a growth chamber. Electrolyte leakage was determined at 12-h intervals with a conductivity meter. To determine chlorophyll, duckweed plantlets (colonies) were removed from the bathing medium, blotted with paper towels, and extracted by incubating overnight in $5 \mathrm{ml}$ of DMSO. Total chlorophyll was determined as described by Hiscox and Israelstam (10) and expressed on a gram fresh weight basis. Growth inhibition was measured by determining duckweed fresh weights at the beginning and end of the experiment. Duckweed bioassay experiments were repeated with three replicates per treatment. Each replicate contained 10 duckweed colonies with each colony containing three fronds. The results are reported as the mean \pm SE of two experiments.

Ultrastructural effects. Duckweed was grown as described previously in half-strength Hutners medium containing $0.05 \%$ DMSO or $0.05 \%$ DMSO plus $50 \mu \mathrm{M}$ apicidin. Tissue was sampled at 12 -h intervals over a 72 -h period. Tissue was placed in a drop of $0.4 \%$ glutaraldehyde fixative in $0.01 \mathrm{M}$ cacodylate acid buffer, $\mathrm{pH} 7.0$, and cut in the fixative with a single edge razor blade. Tissue segments were transferred to a vial containing fresh buffered fixative. Tissue segments were fixed for $1.5 \mathrm{~h}$ and rinsed six times in glutaraldehyde-free buffer thoughout a 1-h period. Tissue segments were then postfixed for $1 \mathrm{~h}$ in $1 \%$ osmium tetroxide in $0.05 \mathrm{M}$ cacodylate buffer, $\mathrm{pH}$ 7.0. After rinsing in distilled water ( dehydrated in a graded acetone series. Once in $100 \%$ acetone, the tissue was embedded and polymerized in Spurr's medium. Semithin sections were obtained with a diamond knife in an ultramicro- tome (Leica Ultracut E; Leica Microsystems, Inc., Bannockburn, IL) and mounted on glass slides, stained with toluidine blue, and observed with a light microscope. Thin sections were stained with uranyl acetate and Reynold's lead citrate and observed and photographed in a transmission electron microscope (Zeiss EM10 CR; LEO Electron Microscopy, Inc., Thornwood, NJ).

Extraction of HD. Duckweed was grown at $23^{\circ} \mathrm{C}$ under constant light (fluorescent, PPFD $=110 \mu \mathrm{E} \mathrm{m}^{-2} \mathrm{~s}^{-1}$ ) in glass baking trays $(34 \times 23 \mathrm{~cm})$ with sterile half-strength Hutners medium, pH 6.0 (12). Every 3 to 4 days, several duckweed fronds were transferred to fresh medium and the remaining plants were frozen in liquid nitrogen and stored at $-80^{\circ} \mathrm{C}$ until extracted for $\mathrm{HD}$ activity. HD was extracted from a total cellular homogenate of duckweed plantlets according to the method of Kolle et al. (15). All steps were performed at $4^{\circ} \mathrm{C}$. Briefly, frozen duckweed tissue $(10 \mathrm{~g})$ was ground in liquid nitrogen with a mortar and pestle. The ground tissue was added to $40 \mathrm{ml}$ of buffer B $(15 \mathrm{mM}$ Tris- $\mathrm{HCl}$, pH 7.8, $10 \mathrm{mM} \mathrm{NaCl}, 0.25 \mathrm{mM}$ EDTA, and $10 \mathrm{mM}$ 2-mercaptoethanol). The solution was brought to $0.7 \mathrm{M} \mathrm{NaCl}$ by adding $8.5 \mathrm{ml}$ of $4 \mathrm{M} \mathrm{NaCl}$ in buffer B. The extract was stirred for $60 \mathrm{~min}$, and filtered sequentially through two layers each of cheesecloth and miracloth. The filtrate was centrifuged $(20,000 \times g, 20 \mathrm{~min})$. Aliquots $(2.0 \mathrm{ml})$ of the resulting supernatant were desalted on

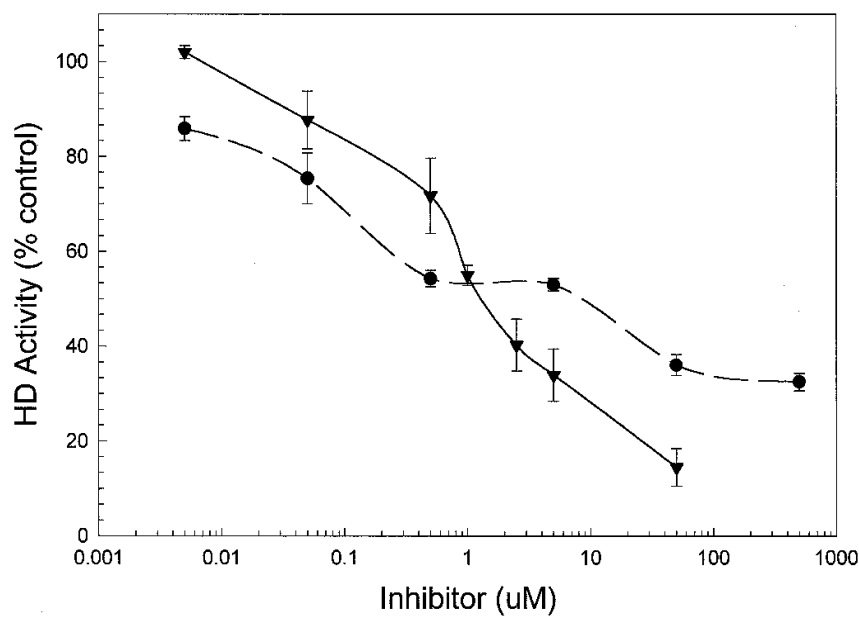

Fig. 2. Effect of apicidin and HC-toxin on histone deacetylase (HD) activity measured in duckweed extracts. Effective concentration $\left(\mathrm{EC}_{50}\right)$ values for apicidin $(\bullet)$ and HC-toxin $(\boldsymbol{\nabla})$ were 5.6 and $1.1 \mu \mathrm{M}$, respectively. Values represent the mean $\pm \mathrm{SE}$ of three separate isolations.

\section{Apicidin}<smiles></smiles>

HC-toxin

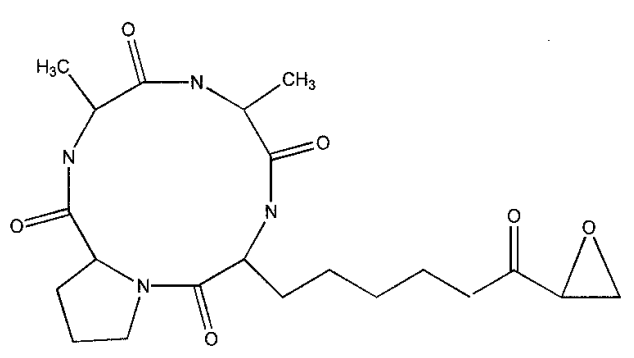

Fig. 1. Chemical structure of apicidin and HC-toxin. 
10-ml Sephadex G-25 columns equilibrated in buffer A. The desalted crude extract was used in the HD assays.

HD assays. The assay mixture $(100 \mu \mathrm{l})$ contained $15 \mathrm{mM}$ Tris- $\mathrm{HCl}$ (pH 7.8), $10 \mathrm{mM} \mathrm{NaCl}, 0.25 \mathrm{mM}$ EDTA, $10 \mathrm{mM}$ 2-mercaptoethanol, 10\% glycerol, 1\% DMSO, $0.06 \mathrm{mM}$ Ac-GlyAla-Lys $\left(\in-\left[{ }^{3} \mathrm{H}\right] \mathrm{Ac}\right)$-Arg-His-Arg-Lys $\left(\in-\left[{ }^{3} \mathrm{H}\right] \mathrm{Ac}\right)-\mathrm{Val}_{-} \mathrm{NH}_{2}$ specific activity $6.6 \mu \mathrm{Ci} / \mu \mathrm{mol})$, and duckweed extract with or without inhibitors (apicidin or HC-toxin) dissolved in 100\% DMSO. The reaction was incubated for $1 \mathrm{~h}$ at $22^{\circ} \mathrm{C}$, and stopped by the addition of $20 \mu \mathrm{l}$ of $1.0 \mathrm{M} \mathrm{HCl} / 0.4 \mathrm{M}$ acetic acid. The reaction was linear during this period. Released $\left[{ }^{3} \mathrm{H}\right]$-acetate was extracted with $0.8 \mathrm{ml}$ of ethyl acetate. After centrifugation $(10,000 \times g$, $5 \mathrm{~min}$ ), $600 \mu \mathrm{l}$ of the organic phase was counted in $5 \mathrm{ml}$ of Ecolume. Uninhibited HD-catalyzed acetate release (approximately $650 \mathrm{dpm} /$ reaction) was determined by subtracting the radioactivity measured in zero extract controls.

\section{RESULTS}

Effects on HD. A high ionic strength buffer described by Kolle et al. (15) was used for extracting HD from duckweed. Previous research demonstrated the requirement for high ionic strength for effective extraction of active HD from a variety of plant tissue sources including maize embryos $(4,15)$. However, because high ionic strength inhibits HD activity (15), it was necessary to desalt the crude duckweed fraction prior to assay. An $\left[{ }^{3} \mathrm{H}\right]$-acetylated $\mathrm{H} 4$ peptide (residues 14 to 21 ) was used as a substrate for in vitro assays. This substrate was previously used to assay for HD activity from calf thymus (13) and E. tenella (7). Using this assay, $\mathrm{EC}_{50}$ values of 1.1 and $5.6 \mu \mathrm{M}$ were determined for HC-toxin and apicidin, respectively (Fig. 2). The pattern of inhibition of in vitro activity differed between the two cyclic tetrapeptides. Apicidin was more effective than HC-toxin at lower concentrations and less effective at high concentrations. At $50 \mu \mathrm{M}$, apicidin and HC-toxin inhibited HD activity by 65 and $85 \%$, respectively. Approximately $30 \%$ of HD activity was not inhibited by $500 \mu \mathrm{M}$ apicidin.

Effects on duckweed. Visual observation indicated that both toxins inhibited growth and chlorophyll synthesis after $72 \mathrm{~h}$ of exposure (Fig. 3). Therefore, effects of $72 \mathrm{~h}$ of exposure to api- cidin $(25$ or $50 \mu \mathrm{M})$ or HC-toxin $(25$ or $50 \mu \mathrm{M})$ on growth, chlorophyll synthesis and membrane permeability (cellular leakage) were examined. At equivalent concentrations, the effects of HCtoxin were greater than apicidin. After $72 \mathrm{~h}$ of exposure to 25 or $50 \mu \mathrm{M}$ apicidin, growth (cell division) was inhibited by 50 and $58 \%$, respectively (Fig. 4A). For HC-toxin, growth inhibition was 71 and $78 \%$, respectively. Chlorophyll concentration in fronds was reduced by 10 and $53 \%$ after $72 \mathrm{~h}$ of exposure to 25 and $50 \mu \mathrm{M}$ apicidin, respectively (Fig. 4B). Again, the effect of equivalent concentrations of HC-toxin was greater than that observed for apicidin with a 72-h exposure to 25 or $50 \mu \mathrm{M}$ HC-toxin, reducing chlorophyll content by 82 and $93 \%$, respectively. At concentrations of 25 and $50 \mu \mathrm{M}$, enhanced cellular leakage of electrolytes was apparent after $24 \mathrm{~h}$ of exposure to both toxins (Fig. 5). Electrolyte leakage from HC-toxin-treated plantlets was greater than from apicidin-treated plantlets.

Effects of apicidin on ultrastructure. A $72 \mathrm{~h}$ time course of the effects of exposure to $50 \mu \mathrm{M}$ apicidin on duckweed frond and root ultrastructure was conducted (Figs. 6 and 7). In frond tissue, $36 \mathrm{~h}$ was the earliest time at which there was a consistent difference between the control (Fig. 6A) and the treated tissue (Fig. 6B). Many organelles in apicidin-treated tissues appear less distinct. The chloroplasts of apicidin-treated tissues contain starch grains that are larger than those of the control tissues.

The treated tissue appeared much the same after $48 \mathrm{~h}$ as it did at 36 h (Fig. 6C). At 60 h, control (Fig. 6D) tissue had dense cytoplasm with normal appearing organelles. Treated tissue (Fig. 6E and F) had less dense cytoplasm, and vacuoles lacked a tonoplast; however, some recognizable organelles were present. At $72 \mathrm{~h}$, controls (Fig. 6G) and treated (Fig. 6H) tissue were very different. Nothing in the treated tissue other than chloroplast membrane remnants, starch grains, and cell wall material was recognizable.

Because duckweed roots were immersed in the treatment solution, they were more directly exposed to apicidin during incubation than were fronds. As a result, effects on root tip ultrastructure were seen earlier during the time course. After $12 \mathrm{~h}$, control root tip cells (Fig. 7A) contain dense cytoplasm with many small vacuoles. Their plastids have well-stained thylakoids, dense stroma, and small starch grains. A light micrograph (Fig. 7A, insert)

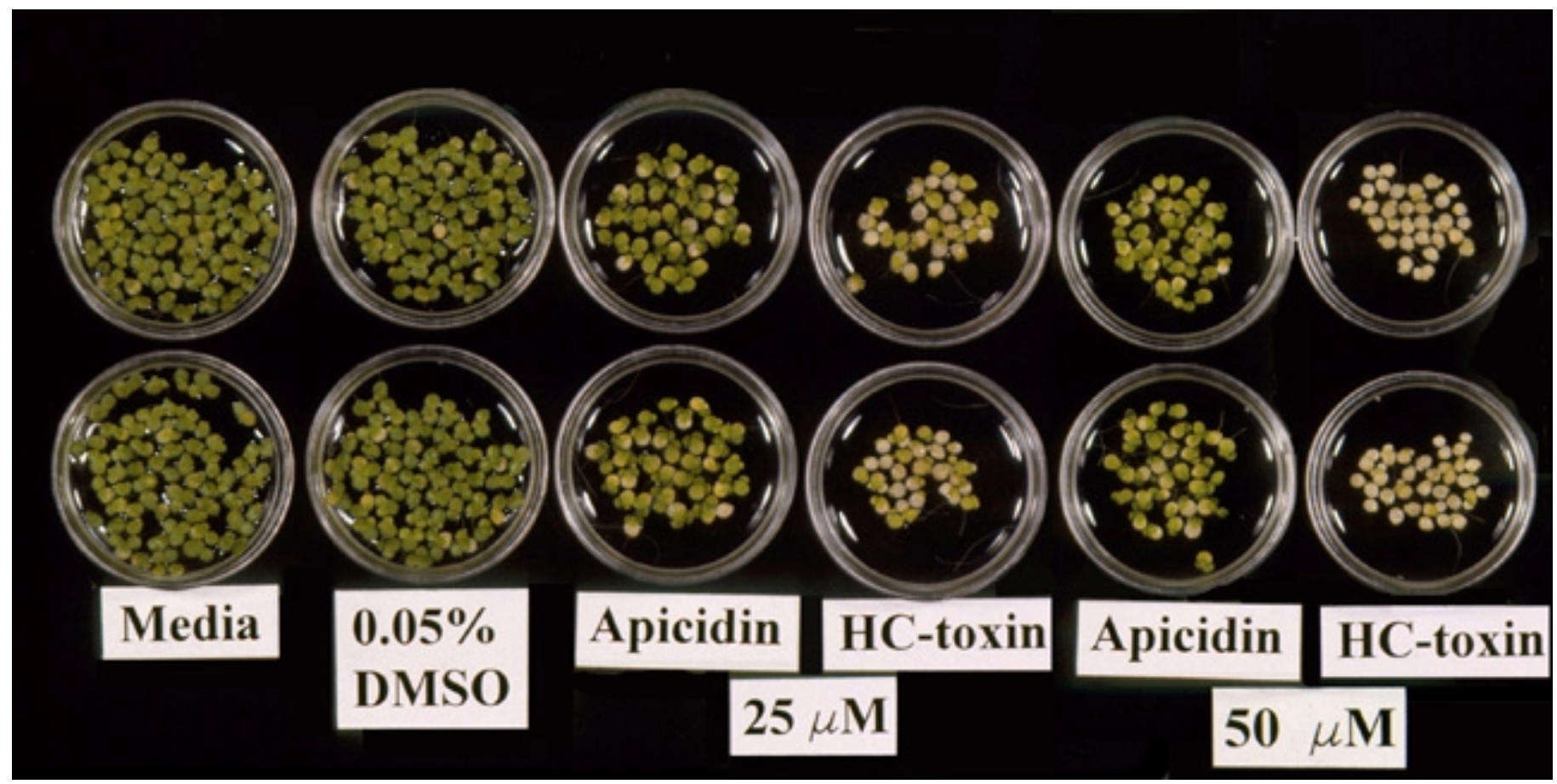

Fig. 3. Effect of 25 or $50 \mu \mathrm{M}$ apicidin or HC-toxin on duckweed growth and chlorophyll synthesis. Visual comparison of the effect of $72 \mathrm{~h}$ of exposure to Hutner's medium alone, medium plus $0.05 \%$ dimethyl sulfoxide (DMSO), or medium containing $0.05 \%$ DMSO plus 25 or $50 \mu \mathrm{M}$ apicidin and HC-toxin. 
shows the contrast between the dense cells of the root tip and the highly vacuolated cells of the root cap. At $12 \mathrm{~h}$, apicidin-treated root tip tissue (Fig. 7B) appears much the same as the untreated controls, except for a slight increase in the number of small vacuoles, although this varies between cells. Treated root tip tissue incubated for $36 \mathrm{~h}$ (Fig. 7C) shows some increase in vacuole size and this effect is observable at the light level. A micrograph of 60-h treated material (Fig. 7D) shows that some root cap material survives with only slight disruptions in ultrastructure (enlarged starch grains and vacuoles). At $72 \mathrm{~h}$ (Fig. 7E), electron micrographs of treated root tip tissue show that displacement of the cytoplasm by enlarged vacuoles has resulted in a spongy appearance. Nuclei and numerous starch containing plastids are discernable. A light micrograph depicts the usual appearance of root tips during longer stages of incubation in the toxin; the root cap is missing, and the root tip itself appears highly vacuolated compared with the control (Fig. 7A, insert). Control root tip tissue harvested at $72 \mathrm{~h}$ (Fig. 7F) is indistinguishable from earlier controls; it has dense cytoplasm with numerous small vacuoles, and all organelles are intact. Their plastids contain well-organized thylakoids and dense stroma.

\section{DISCUSSION}

The results of this study provide, to our knowledge, the first report that the cyclic tetrapeptide apicidin inhibits HD activity in higher plants. The $\mathrm{EC}_{50}$ value for inhibition of duckweed $\mathrm{HD}$ activity was $5.6 \mu \mathrm{M}$. Compared with apicidin, HC-toxin was a more potent inhibitor of duckweed $\mathrm{HD}$ with an $\mathrm{EC}_{50}$ value of

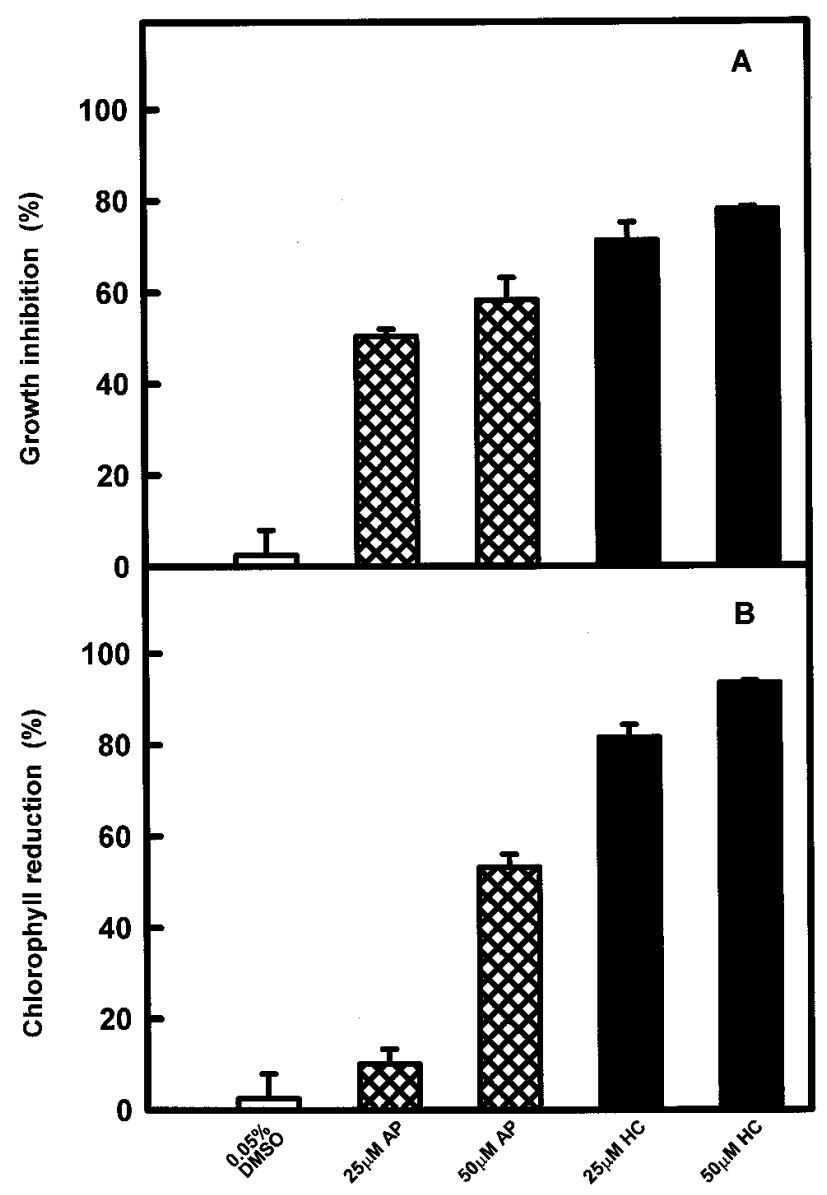

Treatments

Fig. 4. Effects of 72-h treatment with apicidin (AP) and HC-toxin (HC) on $\mathbf{A}$, growth and $\mathbf{B}$, chlorophyll content of duckweed. Growth inhibition and percent chlorophyll were determined on a gram fresh weight basis.
1.1 $\mu \mathrm{M}$. An $\mathrm{EC}_{50}$ value of approximately $5 \mu \mathrm{M}$ was reported for HC-toxin inhibition of HD activity from a partially purified fraction from maize seedlings (5). Apicomplexan HD activity is more sensitive to both toxins than higher plant HD. $\mathrm{EC}_{50}$ values for inhibition of HD from extracts of E. tenella were 0.7 and $30 \mathrm{nM}$ for apicidin and HC-toxin, respectively (7). In contrast to duckweed HD, apicomplexan HD is more sensitive to apicidin than HC-toxin.

In addition to the difference in effectiveness of HC-toxin and apicidin as inhibitors of duckweed HD, the pattern of inhibition also differed. For HC-toxin, inhibition was approximately sigmoidal; however, for apicidin, a biphasic pattern of inhibition was apparent. Apicidin was more effective at inhibiting HD activity at low concentrations, but less effective at high concentrations. Even at $500 \mu \mathrm{M}$ apicidin, approximately $30 \%$ of HD activity was not inhibited.

Maize $(4,5,16)$, pea (25), and yeast (6) have multiple forms of HD. In maize, all forms are equally sensitive to HC-toxin (5). Assuming multiple forms of $\mathrm{HD}$ are present in duckweed, our results suggest that the isoforms do not have equal sensitivity to both toxins. The results suggest that a component (one or more isozymes) of HD activity is not inhibited by apicidin. In yeast, HD isoforms $\mathrm{A}$ and $\mathrm{B}$ differ in sensitivity to the $\mathrm{HD}$ inhibitor trichostatin A (6). Further research with purified higher plant HD isoforms will be required to determine whether apicidin is a selective inhibitor of one or more isoforms.

The effect of cyclic tetrapeptides on duckweed HD was evaluated in vitro by measuring the deacetylation of a highly conserved region (residues 14 to 21 ) of the $\mathrm{H} 4$ histone. The substrate peptide was synthesized and acetylated with $\left[{ }^{3} \mathrm{H}\right]$-acetate. This acetylated octapeptide was previously used as a substrate for evaluating the effect of apicidin on apicomplexan HD (7). Our results suggest that the acetylated $\mathrm{H} 4$ histone peptide is a suitable substrate for higher plant HD. Most studies to evaluate the effects of various inhibitors on higher plant HD used a $\left[{ }^{3} \mathrm{H}\right]$-acetate-labeled total histone fraction from chicken erythrocytes $(5,25)$. However, obtaining this substrate requires considerably more effort than in vitro synthesis and acetylation of the $\mathrm{H} 4$ histone peptide. The $\mathrm{EC}_{50}$ value that we obtained for inhibition of duckweed HD using the acetylated $\mathrm{H} 4$ histone peptide $(1.1 \mu \mathrm{M})$ is similar to that obtained for inhibition of maize $\mathrm{HD}(\approx 5 \mu \mathrm{M})$ using the acetylated chicken erythrocyte histone fraction (5).

Phytotoxic effects of HC-toxin and apicidin were observed at the whole plant level when plantlets were exposed for $72 \mathrm{~h}$ to

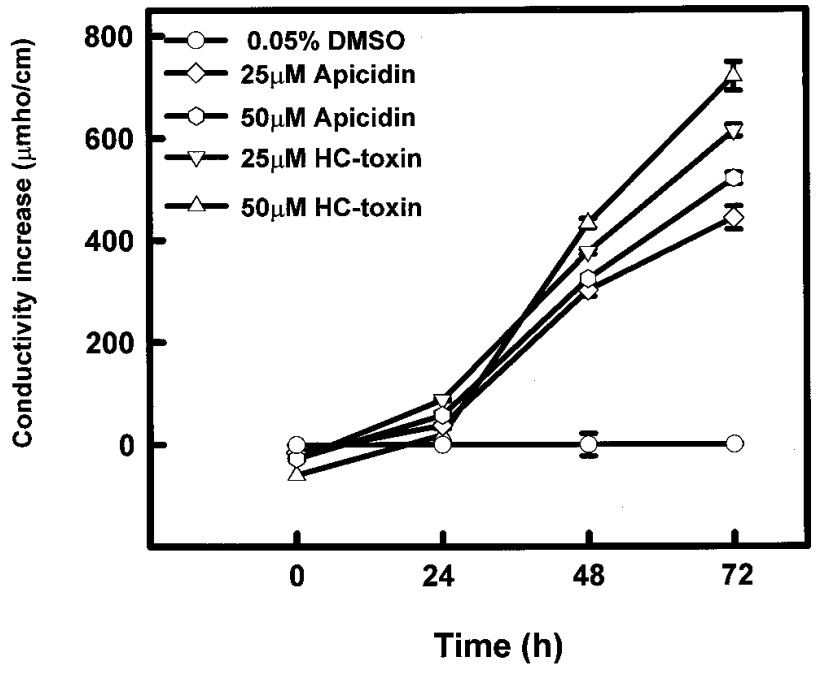

Fig. 5. Time course of effect of apicidin $(25$ or $50 \mu \mathrm{M})$ and HC-toxin (25 or $50 \mu \mathrm{M})$ on cellular leakage of duckweed plantlets as measured by the conductivity increase of the external medium. 
25 or $50 \mu \mathrm{M}$. Based on in vitro assays, $50 \mu \mathrm{M}$ apicidin or HCtoxin inhibited HD activity by 65 and $85 \%$, respectively. It is very likely that internal concentrations of apicidin and HC-toxin were less than external concentrations in the medium due to restrictions in movement of the two cyclic tetrapeptides across membranes. Inhibition of HD by apicidin or HC-toxin would have resulted in hyperacetylation of core histone proteins of duckweed nuclear DNA, which in turn would interfere with gene expression. The
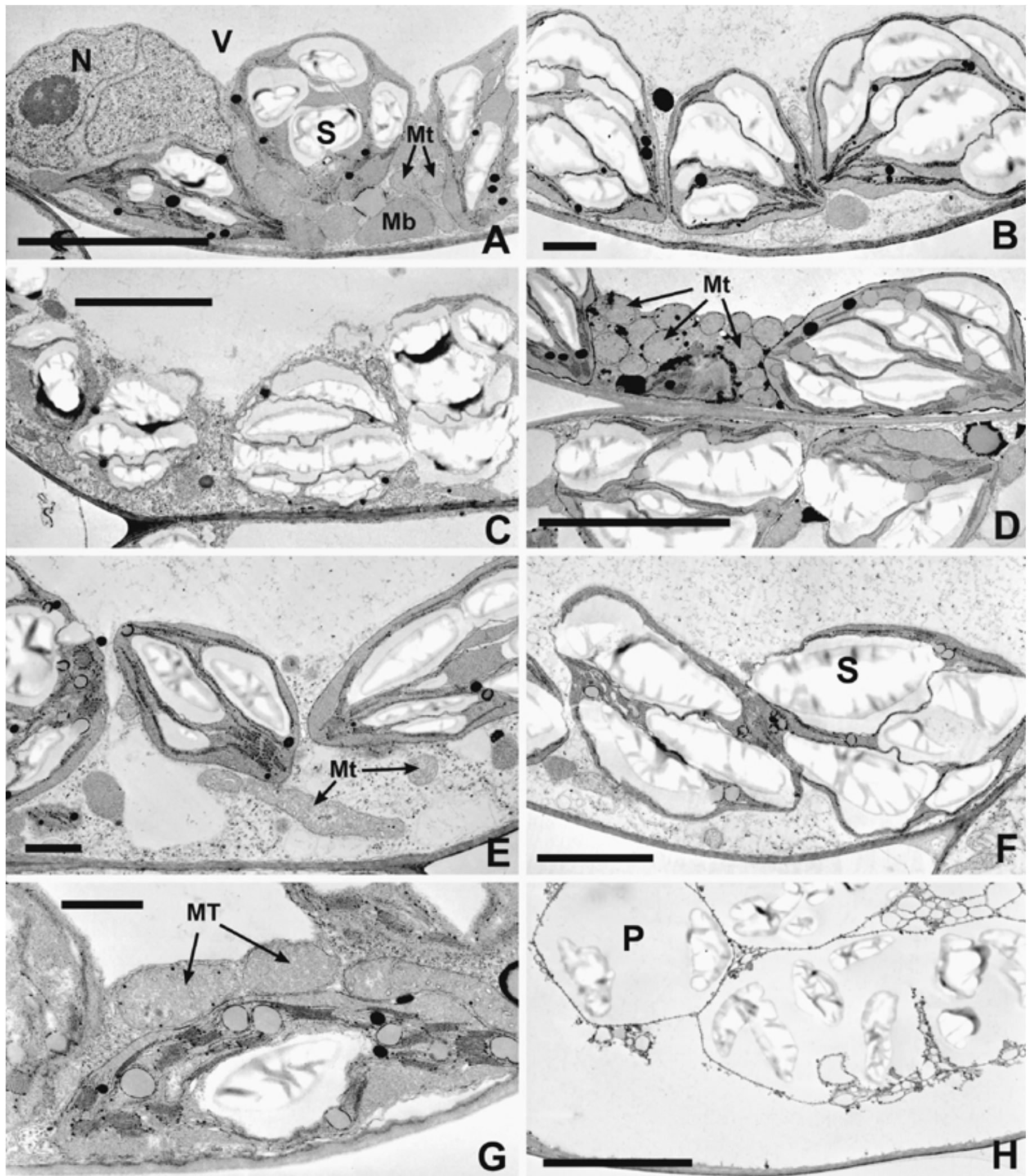

Fig. 6. Ultrastructural effects of $50 \mu \mathrm{M}$ apicidin on duckweed fronds. A, Transmission electron microscopy (TEM) of 36-h control. Plastids, nuclei, mitochondria, and other cytoplasmic organelles are present and in good condition. Bar $=5 \mu \mathrm{m}$. B, TEM of 36-h treated tissue. Plastids appear normal but the cytoplasm is less dense. Bar $=1 \mu \mathrm{m}$. C, TEM of 46-h treated tissue. Plastids and cytoplasm appear more damaged. Bar $=5 \mu \mathrm{m}$. D, TEM of 60-h control. Bar $=5 \mu \mathrm{m}$. E, TEM of 60-h treated tissue. Although cell damage was variable, cytoplasmic integrity was adversely affected. Bar $=1 \mu \mathrm{m}$. F, TEM of 60-h treated tissue. Here, reasonably intact chloroplasts exist in remnants of destroyed cytoplasm. Bar $=2.5 \mu \mathrm{m}$. G, TEM of 72-h control. Bar $=1 \mu \mathrm{m}$. H, TEM of 72-h treated tissue. Although the degree of damage varied among cells, lack of cytoplasm, starch grains, and remnants of chloroplasts was commonly observed. Bar $=5 \mu \mathrm{m}$. 
fact that at both the enzyme and plant level, greater toxicity was observed for HC-toxin than apicidin is consistent with HD being the site of action of both toxins.

At $50 \mu \mathrm{M}$, apicidin or HC-toxin inhibited in vitro HD activity by 65 and $85 \%$, respectively. These toxins also elicited similar levels of inhibition of duckweed growth. After $72 \mathrm{~h}$ of exposure to $50 \mu \mathrm{M}$ apicidin or HC-toxin, growth had been inhibited by 58 and $78 \%$, respectively. Most likely, reductions in plantlet biomass reflect inhibitory effects of both toxins on cell division and daughter cell formation.

Other research has indicated that various HD inhibitors block growth and cell division of both plant and mammalian cells. In maize genotypes susceptible to HC-toxin, root growth (elongation) was inhibited $50 \%$ by approximately $2 \mu \mathrm{M}$ HC-toxin $(17,30)$.
In a resistant maize genotype (homozygous dominant at the $\mathrm{Hm}$ locus), $\mathrm{EC}_{50}$ values were $115 \mu \mathrm{M}$ due to toxin detoxification in planta via carbonyl reductase (17). Apicidin (50 to $100 \mathrm{nM}$ ) inhibited mammalian (HeLa) cell proliferation in vitro by $50 \%$ (7), and HC-toxin $(10 \mathrm{nM})$ caused half-maximal inhibition of cell division of mouse mastocytoma cells (30). Trichostatin A, a Streptomycetes metabolite that blocks mammalian $\mathrm{HD}$, inhibits the cell cycle of rat fibroblasts in the G1 and G2 phases $(31,32)$. Trichostatin A also causes accumulation of acetylated histones species in a variety of mammalian cell lines. Trapoxin, a cyclic tetrapeptide fungal metabolite that inhibits mouse HD, caused accumulation of highly acetylated core histones in a variety of mammalian cell lines, and arrested the cell cycle of rat fibroblasts in both the G1 and G2 phases (14).
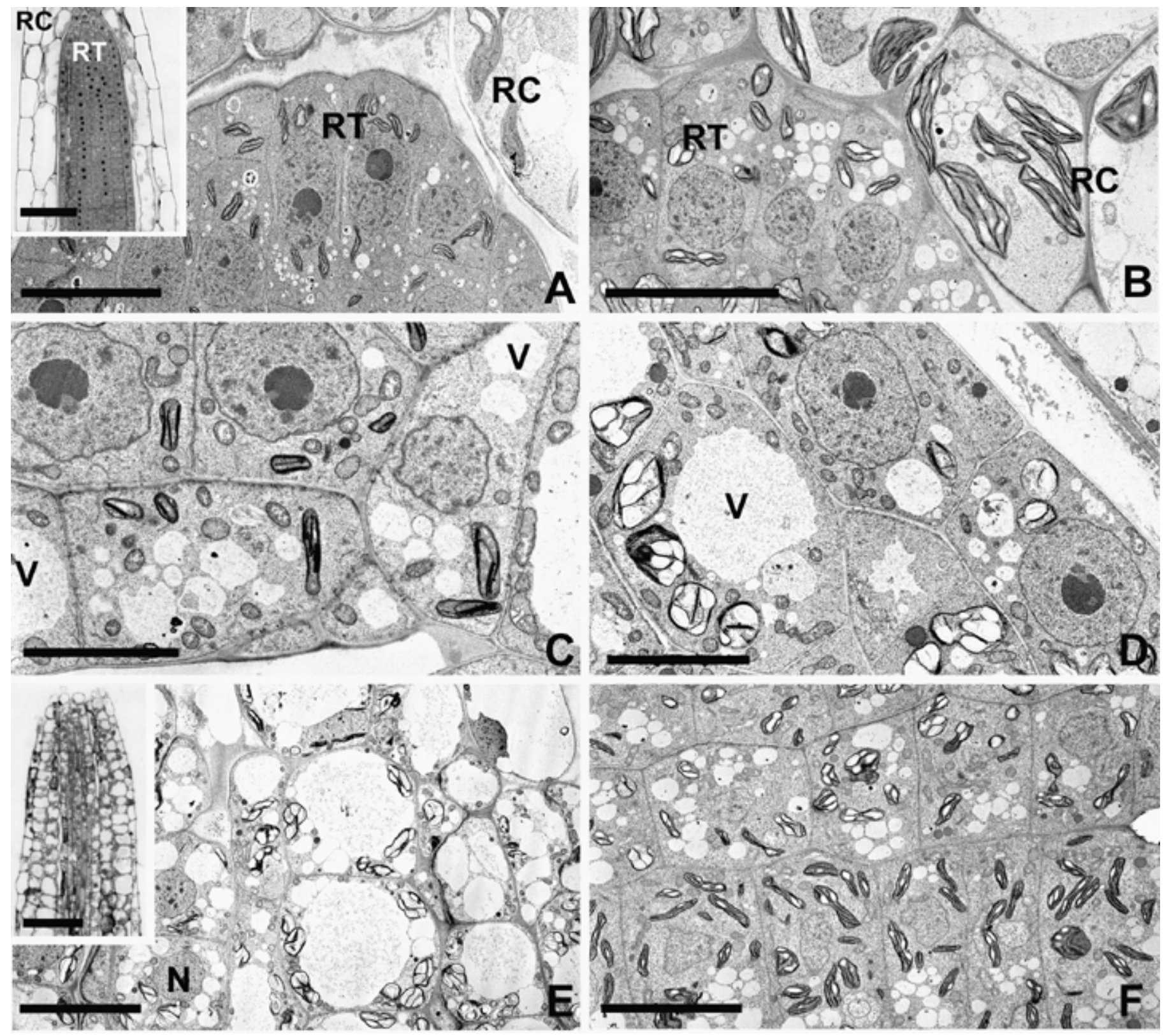

Fig. 7. Light and electron micrographs of control and apicidin-treated duckweed root tips. A, Control root tip (12 h). This tissue is composed of healthy cells in which cytoplasm is dense and contains numerous small vacuoles. The plastids have well stained thylakoids, dense stroma, and a few have small starch grains. Root tip (RT) tissue is very distinct from root cap (RC) tissue in that the latter is highly vacuolated. Bar $=10 \mu \mathrm{m}$. Inset: light micrograph of 12 -h control root tip showing root cap. Bar $=50 \mu \mathrm{m}$. B, Apicidin-treated root tip $(12 \mathrm{~h})$. Except for the slight enlargement of vacuoles, cytosol and organelles appear normal. Bar $=$ $10 \mu \mathrm{m}$. C, Apicidin-treated root tip (36 h). Vacuoles (V) have become even more enlarged. Bar $=5 \mu \mathrm{m}$. D, Treated root tip $(60 \mathrm{~h})$. Cells have enlarged vacuoles and more starch accumulation in plastids. Bar $=5 \mu \mathrm{m}$. E, Apicidin-treated root tip $(72 \mathrm{~h})$. Transmission electron microscopy reveals a spongy appearance to the root, due to displacement of the cytoplasm by vacuoles. Nuclei $(\mathrm{N})$ and numerous starch-containing plastids are present. Bar $=10 \mu \mathrm{m}$. Inset: Light micrograph of 72-h treated root tip in cross section. The root cap is missing and the tissue appears spongy. Bar $=50 \mu \mathrm{m}$. F, Control root tip (72 h). Except for an increase in the size of starch grains in plastids, tissue is very similar to the 12 -h control. Bar $=5 \mu \mathrm{m}$. 
Another major effect of treatment with apicidin and HC-toxin was a reduction in chlorophyll content of duckweed fronds. HCtoxin was more effective at blocking chlorophyll synthesis than apicidin. A 72-h exposure to $50 \mu \mathrm{M}$ apicidin or HC-toxin reduced chlorophyll content of fronds by 53 and $93 \%$, respectively. Previous research demonstrated that HC-toxin $(20 \mu \mathrm{g} / \mathrm{ml})$ blocked chlorophyll synthesis in etiolated leaves of a maize genotype susceptible to Cochliobolus carbonum (24). It specifically blocked the synthesis of $\delta$-aminolevulinic acid, the light inducible and first committed intermediate in chlorophyll synthesis.

To our knowledge, this is the first study to evaluate the effects of an HD inhibitor on the ultrastructure of higher plants. One of the first observable effects of apicidin at the ultrastructural level was its deleterious effects on membranes. Evidence of this was the disappearance of the tonoplast in apicidin-treated fronds and roots. The enhanced electrolyte leakage that occurred in reponse to apicidin treatment suggests that the semipermeability properties of the plasma membrane were impaired. Another effect of apicidin was expressed at the plastid level. In fronds and roots, apicidin treatment resulted in starch accumulation in chloroplasts and plastids, respectively. The starch inclusions continued to enlarge in treated tissue until the later stages of the 72-h time course. This suggests that disruption of photosynthesis is not an early manifestation of the toxin.

Inhibiting duckweed HD with apicidin and HC-toxin suppressed growth, blocked chlorophyll synthesis, and adversity affected ultrastructure. Because HD is thought to play a key role in regulating gene expression, it should not be surprising that HD inhibitors would have diverse and wide ranging effects at the cellular level. Although the results of this study are consistent with the effects of both toxins being due to inhibition of duckweed HD, experiments need to be conducted to determine whether these toxins cause hyperacetylation of nuclear DNA core histones in vivo.

Although there is substantial evidence that HD plays a key role in establishing the acetylation/deacetylation equilibrium of core histones, just how this dynamic equilibrium regulates chromatin structure and DNA transcription is not understood. It is proposed that acetylation of core histones regulates accessibility of chromatin regions to regulatory proteins like transcription factors $(8,19)$. Others have proposed that histone acetylation plays a larger role in the expression of inducible genes than it does with constitutive housekeeping genes (5). Apicidin and HC-toxin may become useful tools to advance understanding of the role of core histone acetylation in regulating DNA transcription and ultimately gene expression.

It is well established that HC-toxin is a critical determinate of the virulence of Cochliobolus carbonum race 1 to maize with the $\mathrm{hm} / \mathrm{hm}$ genotype (29). Earlier research demonstrated that HCtoxin inhibits maize HD both in vitro (5) and in vivo (23). Our results provide further evidence that $\mathrm{HD}$ is the target site of $\mathrm{HC}$ toxin. In vitro assays indicated that HC-toxin was a potent inhibitor of duckweed HD. By regulating the acetylation/deacetylation equilibrium of core (nucleosomal) histones, HD is considered to play an important role in regulating gene transcription $(16,19)$. The mechanism whereby inhibition of HD acts to enhance disease susceptibility of maize with the $\mathrm{hm} / \mathrm{hm}$ genotype is not known. It has been proposed that inhibition of HD by HC-toxin interferes with the expression of genes needed to mount a defense response to Cochliobolus carbonun race $1(5,23)$ Apicidin was recently isolated from F. sambucinum (22) and F. semitectum (26). Although $F$. sambucinum and $F$. semitectum cause disease in potato, strawberry $(11,20)$, and soybean $(9)$, respectively, it has not been established that apicidin plays a role in pathogenicity. Our research showed that apicidin is a potent inhibitor of plant HD. Future research will need to determine whether apicidin is a virulence factor in the diseases caused by these Fusarium spp. and, if so, whether it acts by interfering with plant defense responses as proposed for HC-toxin.

\section{ACKNOWLEDGMENTS}

Mention of a trade name, propriety product, or specific equipment does not constitute a guarantee or warranty by the USDA and does not imply approval of a product to the exclusion of others that may be suitable. We thank B. J. Johnson and M. V. Duke (USDA-ARS, Stoneville, MS) for invaluable technical assistance and T. Krick, Biochemistry Department, University of Minnesota, St. Paul, for performing LC-MS of apicidin and HC-toxin.

\section{LITERATURE CITED}

1. Abbas, H. K., Paul, R. N., Lee, Y. W., and Shier, W. T. 1999. Phytotoxicity of apicidin in duckweed (Lemna pausicostata). (Abstr.) Phytopathology 89(suppl.):S1.

2. Abbas, H. K., Shier, W. T., Seo, J. A., Lee, Y. W., and Musser, S. M. 1998. Phytotoxicity and cytotoxicity of the fumonisin C and P series of mycotoxins from Fusarium spp. fungi. Toxicon 36:2033-2037.

3. Amagasa, T., Paul, R. N., Heitholt, J. J., and Duke, S. O. 1994. Physiological effects of cornexistin on Lemna pausicostata. Pestic. Biochem. Physiol. 49:37-52.

4. Brosch, G., Lusser, A., Goralik-Schramel, M., and Loidl, P. 1996. Purification and characterization of high molecular weight histone deacetylase complex (HD2) of maize embryos. Biochemistry 35:15907-15914.

5. Brosch, G., Ransom, R., Lechner, T., Walton, J. D., and Loidl, P. 1995. Inhibition of maize histone deacetylases by HC-toxin, the host-selective toxin of Cochliobolus carbonum. Plant Cell 7:1941-1950.

6. Carmen, A. A., Rundlett, S. E., and Grunstein, M. 1996. HDA1 and HDA3 are components of a yeast histone deacetylase (HDA) complex. J. Biol. Chem. 271:15837-15844.

7. Darkin-Rattray, S. J., Gurnett, A. M., Myers, R. W., Dulski, P. M., Crumley, T. M., Allocco, J. J., Cannova, C., Meinke, P. T., Colletti, S. L., Bednarek, M. A., Singh, S. B., Goetz, M. A., Dombrowki, A. W., Polishook, J. D., and Schmatz, D. M. 1996. Apicidin: A novel antiprotozoal agent that inhibits parasite histone deacetylase. Proc. Natl. Acad. Sci. USA 93:13143-13147.

8. Durrin, L. K., Mann, R. K., Kayne, P. S., and Grunstein, M. 1991. Yeast histone $\mathrm{H} 4 \mathrm{~N}$-terminal sequence is required for promoter activation in vivo. Cell 65:1023-1031.

9. Hartman, G. L., Sinclair, J. B., and Rupe, J. C. 1999. Compendium of Soybean Diseases. The American Phytopathological Society, St. Paul, MN.

10. Hiscox, J. D., and Israelstam, G. F. 1979. A method for the extraction of chlorophyll from leaf tissues without maceration. Can. J. Bot. 57:13321334.

11. Hooker, W. J. 1981. Compendium of Potato Diseases. The American Phytopathological Society, St. Paul, MN.

12. Hutner, S. H. 1953. Comparative physiology of heterotrophic growth in plants. Pages 417-446 in: Growth and Differentiation in Plants. W. E. Loomis, ed. Iowa State College Press, Ames, IA.

13. Kervabon, A., Mery, J., and Parello, J. 1979. Enzymatic deacetylation of a synthetic peptide fragment of histone H4. FEBS Lett. 106:93-96.

14. Kijima, M., Yoshida, M., Sugita, K., Horinouchi, S., and Beppu, T. 1993. Trapoxin, an antitumor cyclic tetrapeptide, is an irreversible inhibitor of mammalian histone deacetylase. J. Biol. Chem. 268:22429-22435.

15. Kolle, D., Brosch, G., Lechner, T., Lusser, A., and Loidl, P. 1998. Biochemical methods for analysis of histone deacetylases. Methods 15:323331 .

16. Kolle, D., Brosch, G., Lechner, T., Pipal, A., Helliger, W., Taplick, J., and Loidl, P. 1999. Different types of maize histone deacetylases are disinguished by a highly complex substrate and site specificity. Biochemistry 38:6769-6773.

17. Kuo, M. S., Yoder, O. C., and Scheffer, R. P. 1970. Comparative specificity of the toxins of Helminthosporium carbonum and Helminthosporium victoriae. Phytopathology 60:365-368.

18. Lechner, T., Lusser, A., Brosch, G., Eberharter, A., Goralik-Schramel, M., and Loidl, P. 1996. A comparative study of histone deacetylases of plant, fungal and vertebrate cells. Biochim. Biophys. Acta 1296:181-188.

19. Lopez-Rodas, G., Brosch, G., Georgieva, E. I., Sendra, R., Franco, L., and Loidl, P. 1993. Histone deacetylase: A key enzyme for the binding of regulatory proteins to chromatin. FEBS Lett. 317:175-180.

20. Mass, J. L. 1984. Compendium of Strawberry Diseases. The American Phytopathological Society, St. Paul, MN.

21. Melaragno, J. 1974. Anatomical studies on the duckweed, Lemna minor L.-A light and electron microscope investigation with emphasis on ultrastructural details of sieve-element ontogeny. Ph.D. thesis. University of Pittsburg.

22. Park, J. S., Lee, K. R., Kim, J. C., Lim, S. H., Seo, J. A., and Lee, Y. W. 1999. A hemorrhagic factor (apicidin) produced by toxic Fusarium 
isolates from soybean seeds. Appl. Environ. Microbiol. 65:126-130.

23. Ransom, R. F., and Walton, J. D. 1997. Histone hyperacetylation in maize in response to treatment with HC-toxin or infection by the filamentous fungus Cochliobolus carbonum. Plant Physiol. 115:1021-1027.

24. Rasmussen, J. B., and Scheffer, R. P. 1988. Effects of selective toxin from Helminthosporium carbonum on chlorophyll synthesis in maize. Physiol. Mol. Plant Pathol. 32:283-291.

25. Sendra, R., Rodrigo, I., Salvador, M. L., and Franco, L. 1988. Characterization of pea histone deacetylases. Plant Mol. Biol. 11:857-866.

26. Singh, S. B., Zink, D. L., Polishook, J. D., Dombrowski, A. W., DarkinRattray, S. J., Schmatz, D. M., and Goetz, M. A. 1996. Apicidins: Novel cyclic tetrapeptides as coccidiostats and antimalarial agents from Fusarium pallidoroseum. Tetrahedron Lett. 37:8077-8080.

27. Tanaka, T., Abbas, H. K., and Duke, S. O. 1993. Structure-dependent phytotoxicity of fumonisins and related compound in a duckweed bio- assay. Phytochemistry 33:779-785.

28. Tanaka, T., Hatano, K., Watanabe, M., and Abbas, H. K. 1996. Isolation, purification and identification of 2,5-anhydro-D-glucitol as a phytotoxin from Fusarium solani. J. Nat. Toxins 5:317-329.

29. Walton, J. D. 1996. Host-selective toxins: Agents of compatibility. Plant Cell. 8:1723-1733.

30. Walton, J. D., Earle, E. D., Stahelin, H., Grieder, A., Hirota, A., and Suzuki, A. 1985. Reciprocal biological activities of the cyclic tetrapeptides chlamydocin and HC-toxin. Experimentia 41:348-350.

31. Yosida, M., and Beppu, T. 1988. Reversible arrest of proliferation of rat 3 Y1 fibroblasts in both the G1 and G2 phases by trichostatin A. Exper. Cell Res. 177:122-131.

32. Yoshida, M., Kijima, M., Akita, M., and Beppu, T. 1990. Potent and specific inhibition of mammalian histones deacetylase both in vivo and in vitro by trichostatin A. J. Biol. Chem. 265:17174-17179. 